\title{
Actually, What Does “Ontology" Mean? A Term Coined by Philosophy in the Light of Different Scientific Disciplines
}

\author{
Johannes Busse ${ }^{1}$, Bernhard Humm², Christoph Lübbert ${ }^{3}$, Frank Moelter ${ }^{4}$, \\ Anatol Reibold ${ }^{5}$, Matthias Rewald ${ }^{6}$, Veronika Schlüter ${ }^{3}$, Bernhard Seiler ${ }^{6}$, \\ Erwin Tegtmeier ${ }^{7}$, Thomas Zeh ${ }^{3}$

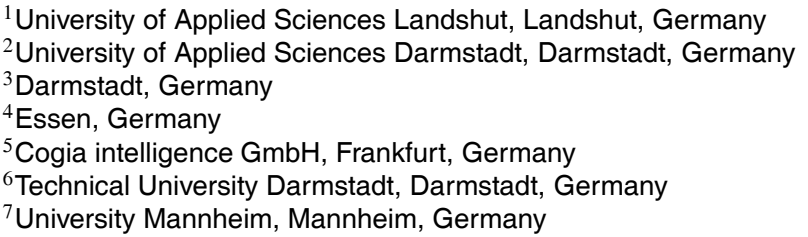

\section{Introduction}

This article is a fictitious, moderated dialogue between an information scientist, a philosopher, and a psychologist. They explore the term "ontology" from the point of view of their own discipline, with the object of learning from each other. The target audience of this article are laypersons with respect to the specific disciplines - but who have a scientific background.

The authors work in the fields of computer science, knowledge engineering, electrical engineering, mathematics, neurobiology, philosophy, and psychology. They are members of the interdisciplinary "Darmstädter Ontologenkreis" (Darmstadt Circle of Ontologists). The article is based on the results of several colloquiums dealing with the concept of ontology in different scientific fields, taking place at the "Darmstadt University of Applied Sciences" since 2010.

The workshop participants discussed the question of how the term "ontology" is used in different scientific disciplines: identically, as a metaphor, or with entirely different meanings. This article is an aggregation of selected colloquium results. The authors try to avoid subject- specific terms, with respect to the interdisciplinary nature of the topic.

Ontology - what does the term actually mean?

Philosopher: The term means the "science of being". Ontology is the most comprehensive of all sciences, insofar as it covers everything that exists. I will go into details later on, but for now: Among philosophers, there is no commonly agreed concept of ontology. The interpretations of philosophers differ just like the multiple ways of looking at "being".

Information scientist: This is also true for computer science. I have found as many as ten essential definitions of ontology. They differ significantly. For examples [1-4], see Table 1: Selected definitions for "Ontology".

We, computer scientists, have adopted the technical term "ontology" from philosophy and use it as an analogy or metaphor. We understand the formal definition of concepts and their relationships as a basis for a common understanding. This is useful for knowledge-based applications.

Psychologist: We rarely use the technical term "ontology" in psychology. However, we inten- 
T. R. Gruber: "An ontology is a formal explicit specification of a shared conceptualization" [1]

M. Uschold, M. Gruninger: "An ontology is a shared understanding of some domain of inter-est." [2]

H. Herre et al.: "Formal Ontology is the science that is concerned with the systematic development of axiomatic theories describing forms, modes, and views of being at different levels of abstraction and granularity." [3]

G. Pickert: "An Ontology is a seven-tuple, $\mathrm{O}:=(\mathrm{L}, \mathrm{C}, \mathrm{R}, \mathrm{F}, \mathrm{G}, \mathrm{H}, \mathrm{A})$ " [5].

With:

C: A set of concepts

$\mathrm{R}$ : Set of binary relations on $\mathrm{C}$ (Relationships between concepts)

F: Function connecting symbol sets to sets of terms

G: Function connecting symbol sets to sets of relations

$\mathrm{T}$ : Taxonomy for the partial ordering of $\mathrm{C}$ in generic concepts / narrower concepts

A: Set of axioms (constraints): statements with elements of $\mathrm{C}$ and $\mathrm{R}$.

Table 1. Selected definitions for "Ontology".

sively deal with concepts and their relationships. We are particularly interested in the question of how people develop concepts and improve them over time.

\section{Ontology Applications and the Semantic Web}

\section{How are Ontologies Utilised in Information Science?}

Information scientist: Basically, wherever you deal with semantics, i.e., the meaning of information. Often, ontologies are used in computer science in the context of the "Semantic Web" [9]. I would like to illustrate the idea behind the Semantic Web by means of an example.
If you go to see a travel agent and ask for a child-friendly hotel at the beach in Northern Germany, the travel agent will offer you familyfriendly hotels that have access to North Sea or Baltic Sea beaches. Of course, he knows that North and Baltic Sea are the two beach areas in Northern Germany.

When I entered "child-friendly hotel at the beach in Northern Germany" at Google a while ago, I found a website with the review of a hotel in Dubai. It was detected because it contained the words "beach", "Germany", and "children". Upon closer inspection I noticed, however, that Germany was the country of origin of the customer who wrote the review, and his profile said "children: none" - hence the match for "children". 1

The travel agent understands the meaning of your question - while a classic search engine just checks for matches of words. I call this a "Syntactic Web": the stupid matching of characters without understanding their meaning.

Semantic Web tries to go a step further. A semantic application for hotel search could deal with the customer's request "child-friendly hotel at the beach in Northern Germany" as follows:

- Linguistic analysis of the request, for example, "Hotel" is a noun, "child-friendly" is an adjective and "with swimming at the beach" and "Northern Germany" are adverbial particles.

- Synonym substitution, for example, "familyfriendly" is something similar to "child-friendly".

- Reasoning, as Northern Germany is a part of Germany, adjoins both North and Baltic sea, seas have beaches etc.

- Matching, in this case, finding hotels that come as close as possible to the description.

So, in contrast to the Syntactic Web, an application of the Semantic Web tries - similar to us humans - to understand and draw conclusions. See also Figure 1: Comparing "Syntactic Web" and "Semantic Web".

\section{Sounds interesting. . .}

\footnotetext{
${ }^{1}$ The experiment was made in German language in 2012. As Google successively introduces semantic aspects into its search, such effects become less frequent.
} 


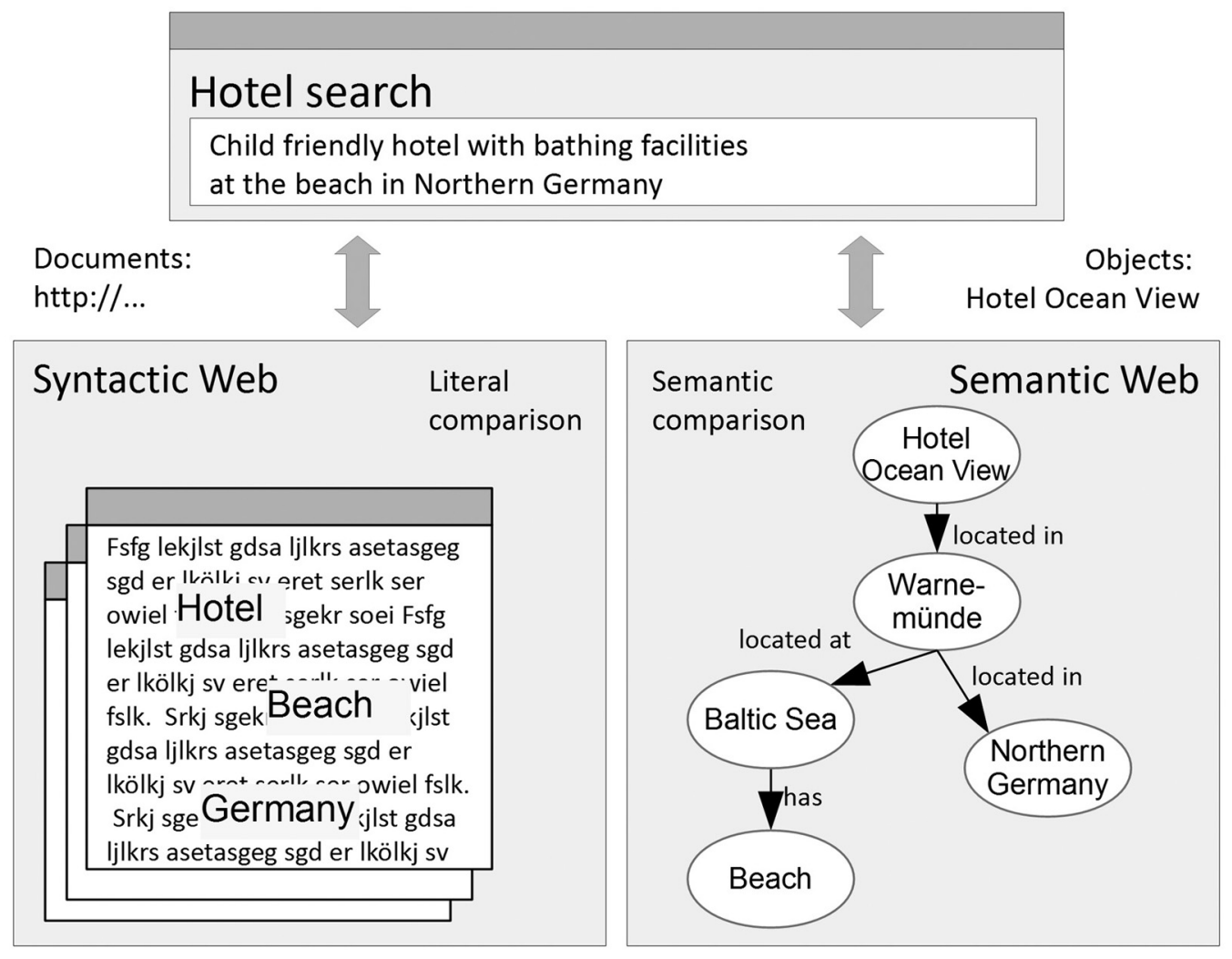

Figure 1. Comparing "Syntactic Web" and "Semantic Web".

Information scientist: Yes, indeed! And that's just the tip of the iceberg.

Since the World Wide Web Consortium has standardized description languages like the Web Ontology Language (OWL), many domain experts all over the world have started formalizing their knowledge in form of ontologies. Hotel owners offer machine-readable semantic descriptions of their accommodations on the web; biologists publish newly discovered genome sequences not only in journal articles, but also in ontologies; laws, court decisions and precedents are specified in a machine-readable form so that they can be processed further. And with intelligent applications based on this information, questions can be automatically answered such as

- Are there family-friendly hotels at the beach in Northern Germany?

- Have genome sequences already been found that are similar to my biological research results? or

- Is there a precedent to my current trial?

\section{How are ontologies utilized for semantic ap- plications?}

Information scientist: Ontologies are the basis for computer applications to communicate among each other and with humans. They even can help humans to communicate among each other [5]. Ontologies are always concerned with a specific domain of interest, for example tourism, biology or law. Ontologies, thus, form a basis for understanding and counteract the confusion of tongues.

In computer science we call an ontology a formal definition of concepts and their relationships, related to a domain of interest. "Formal" means in a language with well-defined syntax and semantics which can be processed by computer programs.

\section{How does such a semantic application work?}

Information scientist: Two main components make up a semantic application: a knowledge base and an inference engine. The knowledge base contains the ontology schema and facts. The ontology schema specifies what types of 
statements are possible and allowed. Both, ontology schema and facts, are expressed in a formal language, e.g., RDFS (Resource Description Framework Schema) or OWL (Web Ontology Language). Of course, the formal languages aren't visible to the end user - but they are necessary for internal processing.

Example of an ontology schema (excerpt):

:Hotel rdf:type rdfs:Class.

Meaning: Hotel is of type "class", hence a concept with instances such as "Hotel Ocean View".

:Location rdf:type rdfs:Class.

"Location" also is a class

:locatedIn rdf:type

owl : TransitiveProperty .

"locatedIn" is a relation, more precisely, a transitive relation.

Examples for facts:

:HotelOceanView rdf:type :Hotel.

"HotelOceanView" is an individual, an instance of the class "hotel"

:Warnemünde rdf:type :Location.

"Warnemünde" is an instance of the class "Location" (a town at the Baltic Sea).

:HotelOceanView :locatedIn

:Warnemünde.

"Hotel Ocean View" is located in Warnemünde

:Warnemünde :locatedIn

:MecklenburgVorpommern.

Warnemünde is located in Mecklenburg Vorpommern, a state in the north east of Germany.

:MecklenburgVorpommern :locatedIn

: NorthernGermany .

"Mecklenburg Vorpommern" is located in "Northern Germany"

Questions can be answered with a query language, for example SPARQL:

SELECT ?hotel WHERE

\{hotel :locatedIn :Warnemünde\}

$\rightarrow$ returns the result

:HotelOceanView, ...

In the simplest case, the knowledge base works like a conventional database: you can ask for the stored facts (here: "Hotel Ocean View is located in Warnemünde").

Things become interesting when inference comes into play. Inference allows inferring new statements from facts by applying inference rules.

A simple inference rule is the transitivity rule: If a relation $\boldsymbol{p}$ is declared as transitive and $\mathrm{x} \boldsymbol{p} \mathrm{y}$ and $\mathrm{y} \boldsymbol{p} \mathrm{z}$ are given, then $\mathrm{x} \boldsymbol{p} \mathrm{z}$ can be inferred.

In our example:

$$
\begin{aligned}
& \text { :locatedIn rdf:type } \\
& \text { owl:TransitiveProperty. } \\
& \text { :HotelOceanView :locatedIn } \\
& \text { Warnemünde. } \\
& \text { :Warnemünde :locatedIn } \\
& \text { MecklenburgVorpommern. } \\
& \rightarrow \text { inference result } \\
& \text { :HotelOceanView :locatedIn } \\
& \text { : MecklenburgVorpommern. }
\end{aligned}
$$

By multiply applying the transitivity rule, the request for hotels in Northern Germany is answered as follows.

$$
\begin{aligned}
& \text { SELECT ?hotel WHERE } \\
& \{\text { ?hotel :locatedIn } \\
& \text { :NorthernGermany } \\
\rightarrow & \text { yields the result } \\
& : \text { HotelOceanView, ... }
\end{aligned}
$$

The transitivity rule is only one of many rules that can be utilized in an inference engine. Such rules allow complex conclusions from given facts. In addition, the ontology developer can specify new, domain-specific rules in a rule language. An example in natural language: "If a hotel has a playground, is offering baby cots and menus for children, then it is considered to be child-friendly". An inference engine uses these domain-specific rules in addition to the built-in rules.

\section{How does an inference engine work?}

Information scientist: Design and function of an inference engine are somewhat complex. Simplified, it works as follows.

1. The input, ontology schema and facts, must be specified in a formal language. In the above-mentioned languages RDFS and OWL, 
e.g., statements are always specified in the form $<$ subject $><$ predicate $><$ object $>$, as in

$$
\begin{aligned}
& \text { :HotelOceanView :locatedIn } \\
& \text { :Warnemünde }
\end{aligned}
$$

Furthermore, the input needs to be syntactically correct. Even small syntactic deviations such as the use of a semicolon instead of a period will result in errors and get rejected.

2. The inference engine loads the ontology schema and facts and represents them internally as a graph. The above example can be illustrated as a graph as in Figure 2.

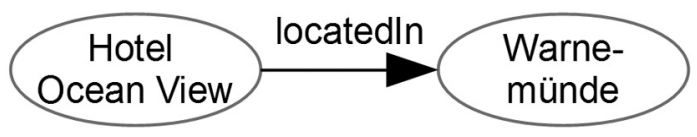

Figure 2. Graphical representation of a statement.

3. A query engine uses an algorithm for matching graphs.

?hotel :locatedIn :Warnemünde is a query graph, which can be matched with the graph

:HotelOceanView :locatedIn

:Warnemünde

by replacing the variable ?hotel by

:HotelOceanView

4. Reasoning is done by chaining a set of rules. A rule is of the form: condition $\rightarrow$ conclusion - just as explained in the example on transitivity.

The application of rules is done by an algorithm for matching graphs. If the condition of a rule can be matched with a sub-graph of the knowledge base, then the inferred statements are added to the knowledge base.

\section{Ontology in Philosophy}

\section{Computer scientists make use of the concept of ontology from philosophy - what does it mean there?}

Philosopher: Literally, "ontology" means "the science of being". The term "ontology" was introduced by Christian Wolf not before the $18^{\text {th }}$ century. But discussing the way how things exist, in a theoretical way -i.e., trying to grasp the world - has been done for at least 2500 years. "To on", the Greek expression for "being", is the most general thing you can say about a subject. The Greek presocratic philosopher Parmenides $(\sim 520-\sim 460 \mathrm{BC})$ was the first one to mention this issue in his essay "On Being". It is ultimately a system of structure in the world of objects and their relations. Categorical ontology, classifying by categories, claims to be an all-encompassing classification system (according to [4]).

\section{Can you, please, give examples?}

Philosopher: Parmenides regards being as "the one" without anything missing. This being is the precondition of any perception.

About 100 years later, Plato $(\sim 428-\sim 348$ BC) developed a dualistic understanding of being: On one hand the (perfect) world of ideas, and on the other hand the imperfect world of things - still derived from the world of ideas by man. The inspection of ideas, the perception, is the substantiation of understanding the world. His allegory of the cave illustrates how, after various concerted and partly painful steps of perception (the blinding sun as a metaphor), true knowledge can eventually be gained - a goal that only a few strive for and achieve. This also shows that any finding which is achieved also means that you cannot possibly "return into the cave".

Plato's student Aristotle (384 - 322 BC), however, categorizes the world by defining ten categories (see Table 2: The ten categories of Aristotle), the most important of which is substance. Substances are organisms with essential and accidental properties. Accidental properties are temporary, non-essential properties (second to tenth category).

Aristotle, actually, was mainly interested in living organisms. Only his successors attempted to make a more comprehensive classification based on his categories. The categories of substance and accidents were kept for centuries, but with fewer and fewer varieties. Descartes only distinguishes between mental and physical properties without any further categorical distinctions.

The Aristotelian categories have structured language for the first time. They form the skeleton for the first explicit grammar ever. 


\begin{tabular}{|c|c|c|c|}
\hline Denomination & Greek & Question & Example \\
\hline Substance & ovoí $\alpha$ (ousia) & What is something? & Man, horse \\
\hline Quantity & $\pi \mathrm{o \sigma ov}($ poson $)$ & $\begin{array}{l}\text { How much/big is } \\
\text { something? }\end{array}$ & Two inches long \\
\hline Qualities & $\pi$ olov (poion) & What are the features? & White, able to read \\
\hline Relation & $\pi \rho \circ \sigma \tau \mathrm{\imath}($ pros ti) & $\begin{array}{l}\text { In what relationship is } \\
\text { something (to something)? }\end{array}$ & $\begin{array}{l}\text { double, half, bigger, } \\
\text { daughter of, was born in }\end{array}$ \\
\hline Location & $\pi \mathrm{ov}(\mathrm{pou})$ & Where is something? & $\begin{array}{l}\text { On the table, } \\
\text { in the swimming pool }\end{array}$ \\
\hline Time & $\pi \mathrm{o} \tau \dot{\varepsilon}$ (pote) & When is something? & Yesterday, in the future \\
\hline $\begin{array}{l}\text { Position/ } \\
\text { orientation }\end{array}$ & $\kappa \varepsilon \iota \sigma \tau \eta \alpha \iota$ (keisthai) & $\begin{array}{l}\text { What orientation does } \\
\text { something have? }\end{array}$ & standing, sitting \\
\hline Having & $\ddot{\varepsilon} \chi \eta \varepsilon ı v$ (echein) & $\begin{array}{l}\text { What does something } \\
\text { have? }\end{array}$ & $\begin{array}{l}\text { Has shoos on his feet, } \\
\text { is armed }\end{array}$ \\
\hline Doing & Totcív (poiein) & What does something do? & Cut, burn \\
\hline Experience & $\pi \alpha ́ \sigma \chi \eta \varepsilon \iota v$ (paschein) & What experiences something? & Being cut, being burned \\
\hline
\end{tabular}

Table 2. The ten categories of Aristotle.

Can you really classify everything there is by means of substances and properties?

Philosopher: For quite a long time it has, indeed, been argued so. Other categories were introduced as subcategories only. But you are correct, at some point in time philosophers found out that something is still missing. Relationships and what whole sentences express are not covered. Therefore, in the 19th century, the additional category "facts" was added.

\section{What are facts?}

Philosopher: The ontologists use them in a broader sense. Not only is it considered to be a fact that A phoned B on May $23^{\text {rd }}, 2012$ at $2: 11 \mathrm{pm}$, but also that all matter underlies gravitational force. Or, similarly, that exactly one natural number is less than 2 and that all natural numbers are either even or odd. Traditional ontologies without fact can only describe the first example in a satisfying way. They tend to shift natural laws into the cognitive awareness or into language.

Well, but what is it good for, classifying the world into things, properties and facts?

Philosopher: Well, these are just subsumptions. Science doesn't just classify. Science primarily searches for laws. The classification is done with respect to these laws in order to avoid categorical mistakes in reasoning, e.g., assuming that a property is located in a particular place.

Take, for example, the green of the leaves of a tree. The green color as an attribute is different from the color layer on a body. The layer only has the characteristic of green color, it is not the property itself. The color layer, in fact, is localized; the abstract property "green" is not, because there are many other things having the same property, but in different places.

Information scientist: Yes, based on our ontologies we have been able to discuss exactly those kinds of questions. Formalized categorical ontologies are called base-ontologies or foundational-ontologies. Base-ontologies are cross-domain-ontology schemes with general concepts such as physical object, property, or range.

Many base-ontologies in computer science are aligned with philosophical findings, terminologies and classifications. A good example is the "Descriptive Ontology for Linguistic and Cognitive Engineering" (DOLCE) [10]. In DOLCE, facts like the green of leaves can be modeled in all its subtleties (see Figure 3: Modelling in DOLCE: "The leave is green"). The relation "has color", e.g., is modeled as a class itself 
which, in turn, may be linked to the class "color region".

So, ontology in philosophy helps me think more precisely. But as there are different ontologies with different categories, which one should I use?

Philosopher: Ontology is an attempt to recognize the world of things and facts in an allencompassing way and to categorize and name everything. Various philosophers have different emphases. In philosophy, as in all sciences, you always find competing theories and a permanent change of theory. If you are looking for orientation, just look for one of the currently popular and accepted ontological theories yourself. The number of choices is not that large.

Information scientist: This similarly applies to base-ontologies in computer science. However, there is no base-ontology claiming to be all-encompassing. So-called bridge-ontologies have been developed to connect different baseontologies. The project "WonderWeb", in which DOLCE has been developed, provides such bridge ontologies (see Figure 4: Base-Ontologies and Domain-Ontologies).
But base-ontologies are not most important for semantic applications. They don't help to answer questions about tourism, biology or law. Additional domain-ontologies are indispensable for that, and these are geared towards their intended use. For example, the ontology "HarmoNET" (The Harmonization Network for the Exchange of Travel and Tourism Information, http://euromuse.harmonet.org) contains a detailed set of terms for describing the features of a hotel.

\section{How People Develop Concepts}

Essential components of ontologies are concepts. How do people actually develop concepts?

Psychologist: When we talk about concepts, two kinds need to be distinguished. Personal concepts are based on the personal experience of a person. This shouldn't be confused with conventional concepts - they are neither identical nor congruent.

Conventional concepts are achieved by agreement among people. Their meaning is attached

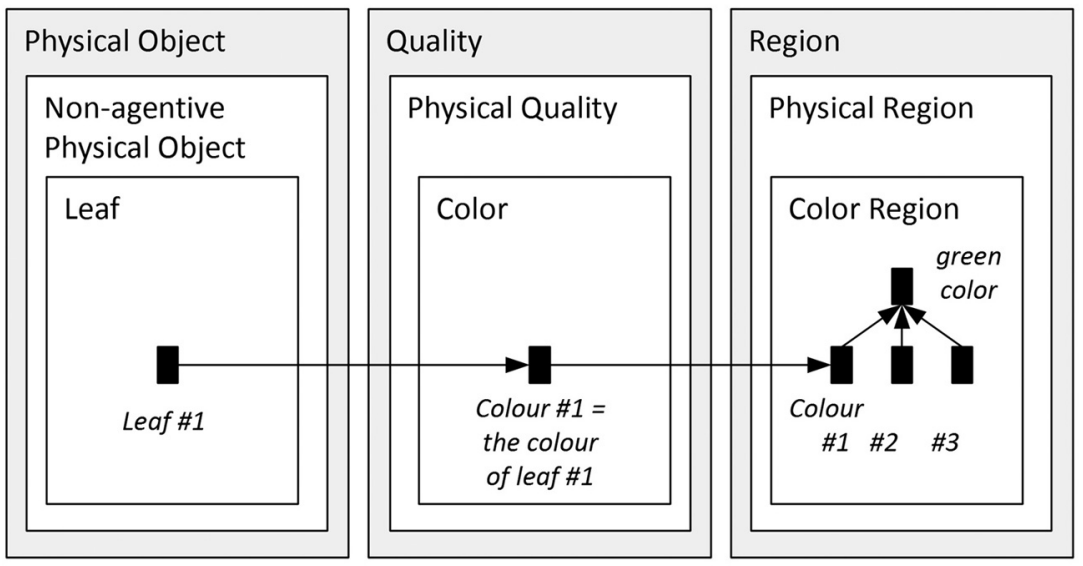

Figure 3. Modelling in DOLCE: "The leave is green" (according to [10, Fig. 3]).

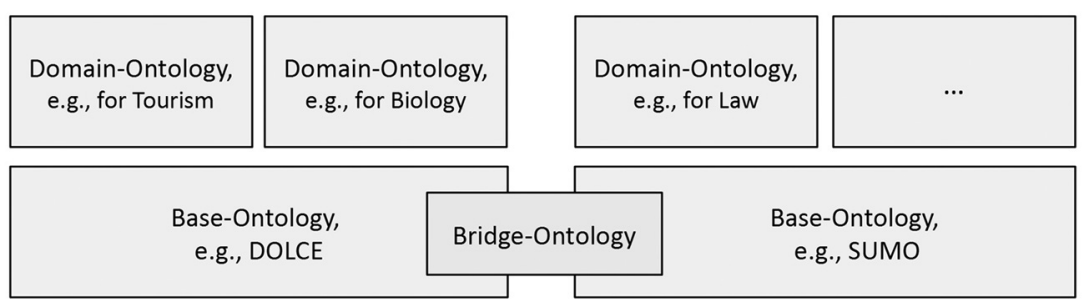

Figure 4. Base-Ontologies and Domain-Ontologies. 
to certain symbols, usually words. Their meaning must be negotiated and roughly defined. The product of negotiation is always an idealized simplification of meanings of the people involved.

Conventional concepts only become personal concepts or knowledge when a single person picks them up and interprets and understands them in his own context. This can never be more than an approximation of the conventional concept. People don't think and judge in terms of conventional concepts - even if they try to get close to this ideal - but always in terms of their personal knowledge.

Personal concepts are not based on the introjection of conventional terms used by the environment, society and culture. Also, personal concepts are not just transferred by language. Personal concepts are independent and specific knowledge and thinking units of each subject. They have been constructed by actively engaging with the environment, but also according to the cultural and linguistic background of the social partners.

The question of how human knowledge and human concepts emerge and evolve is explored, among others, by the field of cognitive developmental psychology. It is related to the question of the origins of world-views. Different movements of psychologists give different answers to your question about the formation of concepts. I can answer it - with respect to the genesis and evolution of personal concepts - in my view and somewhat simplified [11-13] as follows.

The knowledge of people runs through an evolutionary process. The quality of knowledge changes as this process progresses. The evolution starts from simple sensomotoric structures, while adopting the world by acting and perceiving. These structures can be transformed gradually to inner ideas and intuitive knowledge. In what we call "concepts", intuitive knowledge is processed to abstract entities that can be referred to by language. The process of knowledge acquisition is substantially driven by the cognitive structures themselves, by dealing with the perceived and experienced reality and the sociocultural environment, e.g., at school. The (linguistic) input from the social environment is not passively collected, but can only be adapted and processed on the basis of already existing knowledge structures. A metaphor: concepts are like icebergs in the sea of our intuitive knowledge and imagination.

Knowledge acquisition is a tedious process that never ends. Concerning transfer and understanding of conventional (cultural, scientific, linguistic) knowledge, this process can never be more than a process of approximation.

\section{How is this process initiated? How does a child develop its world-view and the related concepts?}

Psychologist: A child develops its world-view by dealing with the experienced reality. The social environment is an essential part of this reality. The child playfully makes hypotheses, gives them a try, and confirms or rejects them. Although a large part of our conceptual knowledge is not based on personal experience, it must be related to our own experience, to our intuitive and pre-existing personal concepts.

\section{Is this also true for an adult?}

Psychologist: Also in adults concepts develop by interacting with the environment - however more consciously, complex, and culturally shaped. Concepts are constantly changing due to the socio-cultural environment and adapt to it. Concepts are in constant flow, within the individual as well as in society.

Imagine an actor playing the role of a doctor in a soap opera telling the audience what he is doing during surgery. Would you trust him to remove your appendix? Of course not! Knowing the text doesn't mean you deeply understand its meaning. Similarly, you cannot transfer knowledge by means of textual definitions.

However, definitions are useful to structure knowledge which has already been acquired, to synchronize it between individuals, and to back it up. Processes as in a brainstorming session may give an idea of what is needed in addition to formally learned knowledge: finding analogies, but not just following strict schedules. It is important to learn to differentiate.

Until now we have been talking about individuals. But concepts play an important role in communication with one another. How is a consensual understanding achieved within communities? How do experts of a discipline, 
like tourism, biology or law, get to a common understanding of concepts and terms?

Psychologist: A common understanding of conventional concepts may evolve by continuously using them within a community. Later on, concepts and terms may be more formally defined, e.g., by standardization agencies. However, this requires a common understanding of the subject.

There are some steps that help to achieve this, e.g.

- Set concepts in relation to other concepts

- Define concepts in contrast to similar concepts

- Compare and find differences

Above all, agreements and standards must prove useful in reality and in interaction with others!

\section{Ontology Engineering: Developing and Communicating Ontologies}

Writing down concepts to formalize them looks like a challenging job to me. How do information scientists go about it?

Information scientist: This is challenging, indeed. The psychologist's metaphor of concepts as icebergs in a sea of our intuitive knowledge and our ideas illustrates this well. Usually, "we don't know what we know".

Knowledge acquisition is the activity, so-called knowledge engineers are performing: in cooperation with domain experts, they verbalize knowledge and write it down. Knowledge must be extracted from the experts' minds, and put on paper or into software tools. The value of an ontology will stand or fall with the level of recognition and approval in the community of experts [7]. In operational practice, verbalization of knowledge is usually connected to the goal to share it, systematically trying to make it conveyable. In a nutshell: An ontology that can not be communicated is a dead ontology.

Our conclusion: knowledge acquisition and knowledge communication are two sides of the same coin, and they are inseparable.

When we, as knowledge engineers, develop an ontology, or more precisely an ontology schema, then the most difficult step is usually the first. An ontology is always bound to a mission, and must support this mission. It would be great if we had criteria to judge whether or not an ontology supports its mission and leads to the intended direction. This, however, would require a complete understanding of the problem domain - an understanding that is often laboriously obtained during the course of the ontology project.

A common mistake is to first write down everything you know and to model whatever can be modeled. Instead, you should always ask for the benefits and only model what is needed for a specific solution to a problem.

Does this mean that you have no methodology for systematically determining which knowledge is missing to solve a particular problem?

Information scientist: Yes, I'm afraid so. This is why we apply methods of knowledge creation where we try to avoid precise definitions in the interim. For this purpose, we start verbalizing knowledge in an informal, "soft" way. A wiki, which is gradually developed, is well suited for this purpose. Terms with fuzzy definitions happen to occur in individual descriptions. They will, eventually, get an entry of their own when they are more precisely defined. They will get interlinked and a semantic network comes into existence.

This wiki approach also corresponds with the observation that a large part of our knowledge cannot completely be represented in a formal way. Instead, formal knowledge always is embedded in knowledge that is communicated in everyday language.

Concepts are almost always fuzzy in human communication. This applies to the extent of a concept (Are roller skates vehicles?), as well as to its characteristics ("Land vehicles have wheels. But what about sleighs?").

A concept may be application - and contextdependent in many ways - even within the same domain. Actually, the meaning of a concept may shift over time. Also there can be regionally different meanings. If relevant to the application, blurs and shifts of meaning must be considered within the ontology. Theoretical approaches to this have existed since the 1990s [6], but their application is still difficult in practice. 
Are ontologies really the best form of knowledge representation?

Information scientist: As I said before, all depends on the task. Ontologies actually don't always adequately represent our knowledge. Often, diagrams, maps, or other knowledge representation mechanisms are better suited to communicate knowledge.

Becoming aware of our own knowledge is usually done on many levels. Within an organization, it is important to identify knowledge holders (people) and sources (media). This is often a project in itself!

Knowledge in organizations is usually established in diverse forms: explicitly in written documents, implicitly in software systems, formal or informal procedures, organizational structures, etc. Imagine you try to find out which business processes are actually established in an organization. This is far more difficult than modeling a process from scratch.

And once we have modeled something conceptually beautiful: How do we share our knowledge with others? How do we document models? How do we communicate them? What can we do in case well-defined concepts are misunderstood by the users? Do we have procedures to improve our models, in particular to find out where they don't work as intended?

I can guess what you mean to say. To find out if an ontology is not appropriate is like having a hammer at hand while dealing with a bolt.

Information scientist: Precisely! Just that hammer and bolt physically refuse to work, whereas conceptual systems - and even more ontologies - are determining our thinking itself. So it is far more difficult to realize its quirks and limits.

Ontologies need to be recorded and read like diagrams or maps. Without appropriate software tools, this quickly becomes a Sisyphean challenge. As with the hammer, the question arises: How can tools support? And where do they become cumbersome and mislead you down the wrong path?

It is best to allow for a diversity of knowledge representations instead of committing to a single one. This is true even in the field of ontology engineering. What we need are different ontologies you can play with, rather than choosing the one ontology which enforces you to subordinate your thoughts and the world.

\section{Who decides on the extent of an ontology? When is an ontology "finished"?}

Information scientist: The extent of an ontology in an IT application is always determined by the context of the application and its goal. The ontology is finished when it delivers the expected benefit to the user. To say that is relatively easy, but this may be difficult in practice. For it raises questions such as: What exactly is the expected benefit? How will expectations develop in future?

I would like to give you an example. In the tourism application mentioned above, one of the requirements was to find matching hotels to questions such as "child-friendly hotel at the beach in Northern Germany". In future, the expectation could be that the application may ask back to the user, e.g., "How old are the children?" in order to find an even better match. Anyway, the use case is limited to hotel search.

This means that the ontology must contain concepts such as hotel, features, location, landmark, etc., as well as statements such as "Hotel Ocean View is located in Warnemünde". But there is no need to include statements like "Hotel workers are humans (homo sapiens)", "humans belong to the order of primates, to the class of mammals, etc., They have a heart, a lung, a liver" and the kind. To include those kinds of (biologically correct) statements in the tourism ontology would not only be unnecessary, but wrong! They do not contribute to the applications purpose and, even worse, cause unnecessary costs for development and maintenance.

So, only relevant aspects should be modeled in an ontology. Relevant is what has benefit. The user (client, stakeholder) decides the use case and, thus, defines what is relevant and what is not.

\section{Summary}

To cut a long story short! What do the concepts of ontology have in common in philosophy, psychology, and computer science? 
Psychologist: We deal with the emergence of concepts and terms in the human minds. However, we use the term "ontology" rarely.

Philosopher, Information scientist: Ontologies describe the world or excerpts thereof in both disciplines. They form the basis for a common understanding and thus facilitate communication. Overall, ontologies help to clarify.

In both disciplines, the world is described by substances and their properties - even though different philosophical schools and computer scientists use different terms. See Table 3: Correspondences between the disciplines.

\begin{tabular}{|l|l|}
\hline Philosophy & Computer Science \\
\hline \hline Substance & Class, entity, concept \\
\hline Accidents & Attribute, property \\
\hline Facts & $\begin{array}{l}\text { Fact, statement, } \\
\text { proposition, relation }\end{array}$ \\
\hline Ontology & $\begin{array}{l}\text { Base-ontology, } \\
\text { foundational ontology }\end{array}$ \\
\hline
\end{tabular}

Table 3. Correspondences between the disciplines.

\section{What are the differences?}

Philosopher, Information scientist: Ontology in philosophy lays claim to being all-encompassing - applying to the whole world. On the other hand, it is without explicit purpose. In contrast, an ontology in information science always aims at benefits. It is usually specific for a domain of interest. This distinction is also reflected in the use of the plural form "ontologies". When philosophers speak of ontologies, they mean all-encompassing world views of various philosophers, e.g., the ontologies of Aristotle, Husserl, etc. When information scientists talk of ontologies, they mean formalizations of different domains (subsets) of the world, e.g., an ontology for tourism, one for biology, or for law.

Do information scientists use the term "ontology" in the same way as philosophers do, or do they use the same term for a different concept (homonym)?

Philosopher, Information scientist: Neither nor. The fact that philosophers and computer scientists do not use the identical concept for the term should have become clear during our discussion (see "Table 4: Differences between the disciplines"). On the other hand, however, the concepts show close similarities (see "Table 3: Correspondences between the disciplines"), hence a homonym is also out of the question, rather analogy or metaphor. The technical term is used in computer science, not in its original, but in a metaphorical meaning. There is a similarity between the two, an association which helps to understand. In computer science, being a young discipline, metaphors from older disciplines are used often. Examples are "architecture" (architecture of buildings $\rightarrow$ software architecture), "surfing" (sport $\rightarrow$ internet research), "virus" (biological virus $\rightarrow$ computer virus) or "mouse" (animal $\rightarrow$ computer mouse).

\section{What have you learned from this dialogue?}

Information scientist: We have already mentioned that we stand on the shoulders of the philosophers when it comes to ontologies.

An essential insight from this dialogue is the distinction between personal and conventional concepts, which is made in psychology. It helps to deal with practical problems in knowledge engineering. Computer science is a young discipline, in particular its sub-discipline of knowledge engineering. Today, we work like the craftsmen in medieval times when they built cathedrals. Our work is based on experience,

\begin{tabular}{|l|l|}
\hline Philosophy & Computer Science \\
\hline \hline In natural language & In a formal language \\
\hline $\begin{array}{l}\text { For debate } \\
\text { (among people) }\end{array}$ & $\begin{array}{l}\text { For processing by machi- } \\
\text { nes, including storage, } \\
\text { retrieval and conclusion }\end{array}$ \\
\hline $\begin{array}{l}\text { Solely abstract, } \\
\text { general (categories) }\end{array}$ & $\begin{array}{l}\text { Both abstract (schema } \\
\text { classes), and -if required } \\
\text { - specific (individuals, } \\
\text { instances, objects) }\end{array}$ \\
\hline $\begin{array}{l}\text { All-encompassing } \\
\text { (describing the } \\
\text { entire world) }\end{array}$ & $\begin{array}{l}\text { Specific (related to } \\
\text { its use) }\end{array}$ \\
\hline $\begin{array}{l}\text { Without explicit } \\
\text { purpose (for the } \\
\text { gain of knowledge) }\end{array}$ & $\begin{array}{l}\text { Benefit-oriented (for a } \\
\text { specific use case) }\end{array}$ \\
\hline
\end{tabular}

Table 4. Differences between the disciplines. 
"best practices", although our results are certainly nothing to be ashamed of. But a scientific foundation to our approach - as the laws of statics for the construction of cathedrals - does not yet exist. For this, I wish and hope for further improvements.

Psychologist: I became aware, again, of the importance of multidisciplinarity. I am happy that as a psychologist, I can contribute to the maturation of a discipline like information science. On the other hand, as said before, in psychology we hardly ever use the term ontology. Still, quite familiar to me is the Babylonian confusion between psychologists: different terms are used for the same concept and - even worse the same term is used for different concepts.

What I have learned today is that other disciplines, like tourism, biology, and law, benefit from the normalization of their terminology by means of ontologies. This could be useful in psychology too, e.g., for indexing and finding scientific publications.

Philosopher: This would be of benefit for philosophy also - in particular for the field of analytical philosophy (e.g., Gottlob Frege, Bertrand Russell and the early Ludwig Wittgenstein). In analytical philosophy, precise concept distinctiveness is most important. Precise concepts require precise tools. Here, the formal ontologies of computer science may be of assistance.

\section{How do you judge the relevance of ontologies in the future?}

Philosopher, Psychologist, Information Scientist: Different disciplines need to grow together more and more. The major challenges of our time - scientific and social - can only be solved interdisciplinarily. To be successful, it is vital that we manage to find results of various teams in various disciplines worldwide and to integrate them reasonably. Ontologies are of vital importance for this: by the power of standardizing terms, their meanings, and relations; furthermore, by the possibility of integrating different domain-ontologies; and, last but not least, by supporting the semantic web in search, reasoning and integration with computer applications. This is why we expect the importance of ontologies to grow significantly in future.

\section{References}

1] T. R. GRUBER, A translation approach to portable ontologies. Knowledge Acquisition, 5(2), pp. 199_ $220,1993$.

[2] M. Uschold, M. GRUNINGER, Ontologies: Principles, Methods and Applications. Knowledge Engineering Review, 11(2), June 1996.

[3] H. Herre eT AL., General Formal Ontology (GFO): A Foundational Ontology Integrating Objects and Processes. Technical Report, 8, University of Leipzig, 2006.

[4] R. Grossmann, The Categorial Structure of the World, Bloomington, 1983.

[5] G. PICKERT, Einführung in Ontologien, http://www.dbis.informatik.hu-berlin.de /dbisold/lehre/WS0203/SemWeb/artikel/2 /Pickert_Ontologien_final.pdf

[6] S. Pollandt, Fuzzy-Begriffe, Formale Begriffsanalyse unscharfer Daten, Springer-Verlag, 1997.

[7] W. Hesse, Aktuelles Schlagwort - Ontologie(n). Informatik Spektrum, 25(6), pp. 477-480, SpringerVerlag, Dezember 2002.

[8] Wikipedia - Die freie Enzyklopädie: Kategorien, http://dewikipediaorg/wiki/Kategorien

[9] T. Berners-LeE, J. Hendler, O. LAssila, The Semantic Web. Scientific American, 284(5), pp. 34-43, 2001.

[10] C. MAsolo et al., WonderWeb Deliverable D17: The WonderWeb Library of Foundational Ontologies, http://wwwloaistccnrit/Papers /DOLCE2.1-FOLpdf

[11] TH. B. SEILER, Begreifen und Verstehen. Ein Buch über Begriffe und Bedeutungen. Darmstädter Schriften zur Allgemeinen Wissenschaft. Verlag Allgemeine Wissenschaft, Darmstadt, 2001.

[12] TH. B. SEILER, Wissen zwischen Sprache, Information, Bewusstsein. Probleme mit dem Wissensbegriff. MV Wissenschaft, Münster, 2008.

[13] TH. B. SEILER, Evolution des Wissens, Bd. 1, Evolution der Erkenntnisstrukturen, Bd. 2, Evolution der Begriffe. LIT-Verlag, Münster, 2012.

Received: October, 2014 Accepted: October, 2014

Contact address:

Prof. Dr. Bernhard Humm Hochschule Darmstadt University of Applied Sciences Haardtring 100 64295 Darmstadt Germany

e-mail: bernhard.humm@h-da.de 
PROF. DR. JOHANNES BuSSE is currently Professor of Knowledge Management at the University of Applied Sciences (HAW) of Landshut, Germany. Before, he held a professorship in Teaching and Learning in Higher Education at the University of Applied Sciences (THM) in Giessen/Friedberg, Germany. He received his diploma and doctorate (Ph.D.), both in Informatics, in 1991 and 1999, respectively, from Tuebingen University, and continued to study at the Graduate College of the Tübingen Interdepartmental Centre for Ethics in Science and Humanities. Following a postdoc position at Heidelberg University, where he focused on blended learning environments in adult education, Johannes Busse worked as Senior Reseracher with Ontoprise GmbH (Karlsruhe) and as free-lance scientific consultant in the areas of semantic web, knowledge management, and ontology engineering. www. jbusse.de

PROF. DR. BERnhaRd HUMm is a professor of software engineering and project management at the Computer Science Department of Hochschule Darmstadt - University of Applied Sciences, Germany. He received a Ph.D. from the University of Wollongong, Australia and the degree Dipl.-Inform. from Kaiserslautern University, Germany. His research focus is on semantic applications, software architecture, and programming languages. He is member of the Board of Directors of the Institute of Applied Informatics, Darmstadt (aIDa) and Ph.D. coordinator. He is running several national and international research projects in cooperation with industry and research organizations and is publishing his results regularly. For 11 years, he worked in the IT industry as a software architect, chief consultant, IT manager and head of the research department of a large software company.

www.fbi.h-da.de/ b.humm

DR. HABIL. CHRISTOPH LÜBBERT, born in 1938, studied mathematics at Technical University Darmstadt and Ludwig-Maximilians-Universität in Munich. He received a doctorate degree in 1969. He was an associate professor of mathematics at Haile Selassie University of Addis Abeba (Ethiopia), and Universidad Nacional del Centro de la Provincia de Buenos Aires (Argentina). Later he worked as a consultant i.a. for the European Commission and the Ministry of the Interior. www.cl-diesunddas.de

DR. FRANK MOELTER, born in 1965 at the Lower Rhine, studied biology in Düsseldorf with the focus on neuroinformatics and neurophysiology. After getting the diploma in biology in 1997 he worked as doctoral candidate and project manager in image processing and pattern recognition at the DMT GmbH in Essen. There he developed a complete OCR system as commercial product, based on parallel artificial neural networks. For the theoretical work he got in 2001 the grade as $\mathrm{PhD}$ from the Westfälische Willhelms University in Münster. Since 2003 he taught for 5 years project management and applied computer science at the Technical University of Applied Sciences in Bochum. He is currently working as a freelance IT consultant for enterprise modeling, IT architecture, project- process- and quality management. In his spare time he works independently on ontology topics and artificial intelligence. www.moelter.cc

ANATOL REIBOLD, born in 1959, graduated in mathematics and mechanics from the University of Novosibirsk. Passionate mathematician with expertise in logic, category theory, ontology engineering, semantic web, data analysis, data science, cryptography, GABEK, polycontextural logic and polyductive theory. www. ontoport.de/?q=de/node/3

MatTHIAS ReWALD, Dipl.-Ing., born in 1955, studied electrical engineering at the Technical University Darmstadt. Worked in the fields of software development, process engineering, computer aided manufacturing, software ergonomics, project management, document and information management and training. At present: running the business of the "Ernst-Schröder-Zentrum für begriffliche Wissenverarbeitung" (Ernst Schröder Center for Conceptual Knowledge Processing) and tutor. www.ernstschroederzentrum.de
DR. VERONIKA SCHLÜTER was born in Wilhelmshaven. She studied philosophy, French language and literature and Geography at the universities in Kiel, Saarbrücken, Paris and Poitiers. She made a Phd in philosophy and worked on categories. ("Über Kategorien und ihre Herausbildung"). She completed her university studies with a state examination and worked as a teacher at a Grammar School. She is now a retired person, but continues to work on philosophy, ontology and teleology. She has two children and two grand-children.

Prof. Dr. Thomas Bernhard SeILER is a Professor emeritus of Psychology at the Technical University Darmstadt. Born in 1925 at Dietikon near Zurich, Switzerland, he first studied philosophy and theology, then received degrees in mathematics, physics, botanic and French literature. Finally he had concentrated on psychological sciences at the Universities of Fribourg (Switzerland), Paris and Berlin, and written a thesis on reversibility. In 1971 he obtained the position of Professor of Developmental Psychology at the Free University of Berlin, and in 1976 went to Darmstadt. His main research topic was the development of concepts and word meanings. In the last years he concentrated on philosophical and psychological theories of concepts and meanings. www.seiler-auerbach.de

PROF. DR. ERWIN TEGTMEIER graduted from the University of Frankfurt (supervisor Habermas), majors: Sociology and Social Psychology, minors: Political Science and East European History. PhD with Hans Albert in Philosophy of Science. Current position: Professor of Philosophy at the University of Mannheim. Areas of research: philosophy of science, ontology and its history, theory of knowledge. www.metaphysica.de/personen/e-tegtmeier.htm

THOMAS ZEH, Dipl.-Math., studied mathematics, operations research, and computer science at the Technical University of Darmstadt. He worked as a data manager at the chemical-pharmaceutical company E. Merck. He published papers about data warehousing and quality assurance. He is also interested in philosophy and interrelations between disciplines. Thomas Zeh was born in 1946, lives in Darmstadt, is married, and has a daughter and a grandchild. www.tzeh.de 
